\title{
Yaşıı bireylerin kronik ağrıyla baş etme durumları ve etkileyen faktörlerin incelenmesi
}

\author{
Examination of elderly people's coping with chronic pain and affecting factors \\ Emine Karaman ${ }^{1}$ Kadriye Sayın Kasar ${ }^{2}$ Hëlya Kankaya ${ }^{1}$ (D) \\ ${ }^{1}$ Ege Üniversitesi, Hemşirelik Fakültesi, İç Hastalıkları Hemşireliği Anabilim Dalı, İzmir, Türkiye \\ ${ }^{2}$ Aksaray Üniversitesi, Sağlık Bilimleri Fakültesi, Hemşirelik Bölümü, İç Hastalıkları Hemşireliği \\ Anabilim Dalı, Aksaray, Türkiye
}

\section{Öz}

Amaç: Bu çalışmanın amacı, yaşlı bireylerin kronik ağrıyla baş etme durumları ve etkileyen faktörlerin incelenmesidir.

Gereç ve Yöntem: Tanımlayıcı ve kesitsel tipteki bu çalışmaya, 97 yaşlı birey dâhil edilmiştir. Çalışma, Ocak-Mart 2020 tarihleri arasında bir eğitim ve araştırma hastanesinde gerçekleştirilmiştir. Veriler, Birey Tanıtım Formu, Visual Analog Skala (VAS) ve Ağrıyla Baş etme Envanteri (ABE) kullanılarak toplanmıştır.

Bulgular: Çalışmanın örneklemini oluşturan bireylerin yaş ortalaması $73,11 \pm 7,15$ yıldır. Yaşlı bireylerin yaklaşık yarısı $(\% 46,4)$ diz/bacak ağrısı yaşamakta, bunu \%32,9 ile sırt/bel ağrısı

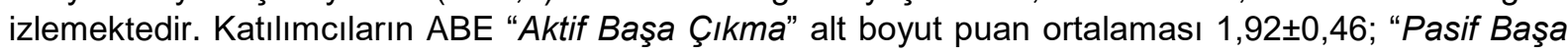
Çıkma" alt boyut puan ortalaması 2,56 $\pm 0,61$ 'dir. Bireylerin Aktif Başa Çıkma strateji toplam puanı ile herhangi bir değişken arasında anlamlı fark bulunmamaktadır $(p>0,05)$. Pasif Başa Çıkma strateji toplam puanı ile yaş, eğitim durumu, ağrı bölgesi, kullandığı ilaç grubu, ağrıyı arttıran ve azaltan durumlar açısından anlamlı fark bulunmazken ( $p>0,05)$; cinsiyet, medeni durum, çalışma durumu, gelir düzeyi, ağrıya yönelik ilaç kullanımı ve genel sağlık durumu arasında anlamlı bir fark bulunmaktadır $(p<0,05)$.

Sonuç: Bu çalışmanın sonucunda, yaşlı bireylerin en çok diz ve bacak ağrısı yaşadığı ve ağrıyla baş etme durumunu bazı bireysel ve ağrıya ilişkin faktörlerin etkilediği bulunmuştur. Yaşlı bireylerin pasif baş etme stratejilerini, aktif baş etme stratejilerine göre daha fazla kullandığı görülmektedir. Bu konuda mevcut durumu ortaya koyan bu çalışmanın, farkındalık oluşturmaya ve yaşlı bireylerin yaşam kalitesini arttırmaya yönelik stratejilerin geliştirilmesine katkı sağlayacağı düşünülmektedir.

Anahtar Sözcükler: Ağrı, aktif ve pasif baş etme, yaşlı.

\section{ABSTRACT}

Aim: The aim of this study was to investigate the factors influencing the situation and to cope with chronic pain in the elderly.

Materials and Methods: This descriptive and cross-sectional study included 97 elderly individuals. The study was carried out in a training and research hospital between January and March 2020. Data were collected using the Individual Identification Form, the Visual Analogue Scale (VAS) and the Pain Coping Inventory (PCI). 
Results: The average age of the individuals who make up the sample of the study is $73.11 \pm 7.15$ years. Approximately half of the elderly (46.4\%) experienced knee / leg pain, followed by back / lumbar pain with $32.9 \%$. Participants' $\mathrm{PCl}$ active pain coping strategies sub-dimension mean score was 1.92 \pm 0.46; passive pain coping strategies subscale mean score was found to be $2.56 \pm 0.61$. There is no significant difference between the active pain coping strategies total score of individuals and any variable $(p>0.05)$. While there was no significant difference between passive pain coping strategies total score and age, educational status, pain zone, drug group used, conditions that increase and decrease pain ( $p>0.05)$; there is a significant difference between gender, marital status, employment status, income level, pain medication use and general health status $(p<0.05)$.

Conclusion: At the end of this study, it was found that elderly individuals experienced the most knee and leg pain and some individual and pain-related factors affected their pain coping status. It is observed that elderly individuals use passive coping strategies more than active coping strategies. It is thought that this study, which reveals the current situation on this subject, will contribute to the development of strategies for raising awareness and increasing the quality of life of elderly people.

Keywords: Pain, active and passive coping, elderly.

\section{GíRiş}

Biyolojik düzeyde yaşlanma, zamanla artan çeşitli moleküler ve hücresel hasarların etkisinden kaynaklanmaktadır (1). Bu süreç, fiziksel ve zihinsel kapasitede kademeli bir düşüş ve genel olarak biyolojik, fizyolojik, duygusal, psikolojik ve fonksiyonel boyutları içermektedir. Yaşlılık döneminde yaşanan bu değişiklikler sağlık sorunlarını da beraberinde getirebilmektedir (1, 2). Bu sağlık sorunlarından biri de yaşlı bireyin yaşam kalitesini olumsuz yönde etkileyen kronik ağrıdır (1-3). Ağrının görülme sıklığı yaşla birlikte artmaktadır (4). Ancak, yaşlı bireylerde ağrının birden fazla nedeni olabildiğinden sıklığı tam olarak bilinmemektir $(6,7)$. Yaşanan ağrıların aktiviteden kaçınma, hareketliliğin azalması ve izolasyon, düşme, uyku bozukluğu, depresyon ve anksiyete ile ilişkili olduğu belirtilmektedir (7-9). Bunun yanı sıra ağrının olumsuz etkilerinin yaşlının ötesine geçtiği, aile ve toplum üzerinde de sosyo-ekonomik yük oluşturduğu vurgulanmaktadır (10).

Toplumda yaş artışı ile birlikte ağrılar normal bir yaşam olayı olarak algılanmakta, sağlık çalışanlarının da çoğunun görüşünün bu yönde olması ağrının ifade edilmesi ve etkili baş edilmesini güçleştirmektedir. Bunu destekler bir veri olarak, yaşlı bireylerin deneyimledikleri ağrıları yaşlarına bağladıkları ve destek sağlık hizmeti alma girişiminde bulunmadıkları belirtilmektedir (11). Kronik ağrı hem kendi başına hem de sonuçları itibariyle bireylerin hayatlarında strese neden olmaktadır. Bu nedenle ağrıyla etkin baş edebilme önemlidir.
Ağrıyla baş etmede aktif ve pasif olmak üzere iki farklı yöntemden bahsedilmektedir. Aktif baş etme yöntemleri, ağrının şiddetini azaltmak ve ağrıyı yönetebilmek, bireyin işlevselliğini sürdürebilmek için uygulanan yöntemlere karşılık gelmektedir. Geri çekilme, kaçınma ve dinlenme gibi pasif baş etme yöntemlerinin ise ağrı üzerinde etkili olabileceğine inanılmamaktadır. Ayrıca pasif yöntemlerin fiziksel işlevde bozulma, psikolojik streste artma gibi olumsuz sonuçlara neden olabileceği belirtilmektedir (12-14). Bu yöntemler uygulandıkları duruma ve kullanılma sıklıklarına göre ağrı ile baş etme sürecini olumlu ya da olumsuz etkileyebilmektedir (3).

Ağrısı olan yaşlı bireylerin bakımında önemli sorumluluklar üstlenen hemşirenin, hastaların ağrıyla baş etme davranışları ve etkileyen faktörleri bilmesi önemlidir. Çünkü ağrısı olan bireyle karşılaşmak hemşireler için stres yaratan bir durumdur $(15,16)$. Ağrı ile baş etmenin karmaşık bir süreç olduğu düşünülmektedir. Bu kapsamda bu çalışma, yaşlı bireylerin kronik ağrıyla baş etme durumları ve etkileyen faktörlerin incelenmesi amacıyla yapılmıştır.

\section{GEREÇ ve YÖNTEM}

Tanımlayıcı ve kesitsel tipteki bu araştırmanın evreni, Ocak-Mart 2020 tarihleri arasında bir eğitim ve araştırma hastanesinin dâhiliye klinik/polikliniklerine çeşitli nedenlerle başvuran 65 yaş ve üzeri bireylerden oluşmaktadır. Çalışmanın örneklemini ise; Ocak-Mart 2020 tarihleri arasında çalışmaya dâhil edilme kriterlerine uyan ve araştırmaya katılmaya 
gönüllü olan 97 yaşlı birey oluşturmuştur. Araştırmaya dâhil edilme kriterleri; (1) 65 yaş ve üzeri olma, (2) en az 3 aydır ağrı şikâyeti olma, (3) sorulara cevap verebilecek bilişsel yeterliliği olma, (4) işitme vb iletişim sorunu olmama ve (5) çalışmaya katımaya gönüllü olmamasıdır. Dışlama kriterleri ise, hastanın soruları cevaplayamayacak düzeyde bilişsel ve psikiyatrik bir rahatsızığının olması ve kanser tanısı almış olmasıdır. Çalışmada örnekleme yöntemi olarak olasılıksız yöntemlerden gelişigüzel örnekleme yöntemi kullanılmış olup, Ocak-Mart 2020 tarihleri arasında araştırmaya alınma kriterlerine uyan yaşlı bireyler çalışmaya dâhil edilmiştir. Çalışmada örneklem hesabına gidilmemiş olup, belirlenen tarihler arasında çalışmaya alınma kriterlerine uyan bireyler çalışmaya alınmıştır. Araştırmanın bağımlı değişkenleri kronik ağrıyla baş etme durumları, bağımsız değişkenleri ise etkileyen faktörlerdir (sosyo-demografik ve hastalık özellikler).

\section{Verilerin Toplanması}

Veriler, "Birey Tanıtım Formu", "Visual Analog Skala (VAS)" ve "Ağrılla Baş etme Envanteri (ABE)" kullanılarak yüz yüze görüşme tekniği ile toplanmıştır.

Birey Tanıtım Formu: Bu form; araştırmacılar tarafından literatüre $(3,6,14)$ dayalı olarak hazırlanmış olup, bireylerin sosyo-demografik özelliklerine ve hastalık durumlarına ilişkin sorulardan oluşmaktadır.

Visual Analog Skala (VAS): Sayısal olarak ifade edilemeyen bazı değerleri sayısal hale çevirmede pratik olan bu gösterge çizelgesi ağrının şiddetinin belirlenmesinde kullanılmaktadır. Değerlendirilen ağrının şiddeti için, genellikle 0 puan "ağrı yok" ve 10 puan "hayal edilebilecek en kötü ağrı" şeklinde değerlendirilmektedir (10 cm'lik ölçek) (17). Elde edilen puanın değerlendirmesinde $<3$ hafif ağrı, 3-6 arası orta şiddette ağrı, $>6$ ise şiddetli ağrı anlamına gelmektedir (18).

Ağrıyla Baş etme Envanteri (ABE): Kraaimaat ve Evers tarafından 2013 yılında geliştirilen ölçek, kronik ağrı yaşayan bireylerin ağrıyla baş etmede davranışsal ve bilişsel yöntemleri ne sıklıkla kullandıklarını değerlendirmektedir (19). Ölçekte alınan puan artıkça, ağrıyla baş etme davranışlarının kullanılma oranı da artmaktadır. Ölçeğin özgün formu ağrıyı dönüştürme, uzaklaşma ve talep azaltma şeklinde aktif; geri çekilme, endişelenme ve dinlenme şeklinde pasif olarak altı alt boyuttan oluşmaktadır $(3,19)$. Ölçek puanlaması, 1 (neredeyse hiç) ile 4 (çok sık) arasında yapılmaktadır. Ölçeğin Türkçe geçerlik ve güvenirlik çalışması, Hocaoğlu ve arkadaşları tarafından yapılmıştır (3). Alt boyutlar, madde sayısına bölünerek puanlanmaktadır. Ölçeğin alt boyutlarının Cronbach Alpha iç-tutarlıık katsayıları "uzaklaşma" için 0.76, "ağrıyı dönüştürme" için 0.77 , "rahatlatıcı düşünme" için 0.53 , "endişe" için 0.69 , "dinlenme" için 0.73 ve "geri çekilme" için 0.61 olarak hesaplanmıştır (3).

\section{Verilerinin Değerlendirilmesi}

Verilerin değerlendirilmesi SPSS 22.0 istatistik programı ile yapılmıştır. Veri toplama formlarından elde edilen ordinal veriler aritmetik ortalama, standart sapma, minimum, maksimum değerler şeklinde; nominal veriler frekans ve yüzde şeklinde verilmiştir. Araştırmada ölçek toplam puan ve alt boyut puan ortalamaları ile bağımsız değişkenler karşılaştııılmış, verilerin normal dağılıma uygunluğu değerlendirilmiştir. Normal dağılıma uymayan veriler değişkenlerdeki gruplara bağlı olarak, bağımsız gruplarda MannWhitney $U$ ile Kruskal-Wallis testleri ile analiz edilmiştir. Sonuçlar, \%95 güven aralığında değerlendirilmiş, anlamlılık düzeyi $p<0.05$ alınmıştır.

\section{Araştırmanın Etik Yönü}

Çalışma, Helsinki Bildirgesi'nin etik standartlarına uygun olarak yürütülmüştür. Araştırmanın yapılabilmesi için bir üniversitenin insan araştırmaları etik kurulundan izin alınmıştır (2019/10-13). Ayrıca çalışmanın yapıldığı kurumdan kurum izni ve ölçek sahibinden kullanım izni alınmıştır. Örnekleme dâhil edilen yaşı bireylere çalışma öncesinde araştırmanın amacı açıklanmış ve onamları alınmıştır.

\section{BULGULAR}

Çalışmaya katılan bireylerin yaş ortalaması 73,11 $\pm 7,15$ 'dir (min 65-maks 91). Katılımcıların yarısından fazlası $(\% 56,7)$ kadın olup; \%87,6'sı evli, \%52,6'sı ilköğretim mezunu, \%88,7'si çalışmıyor ve $\% 58,8$ 'i orta gelir düzeyine sahip olduğunu ve \%61,9'u eşi ile birlikte yaşadığını bildirmiştir (Tablo-1). Katılımcıların ortalama VAS puanı 6,34 $\pm 2,03$ (min. 2-maks. 10) olarak saptanmıştır. 
Tablo-1. Ağrıyla baş etme envanteri (ABE) aktif ve pasif ağrıyla başa çıkma boyutlarının bazı sosyo-demografik özelliklere göre karşılaştırııması $(n=97)$.

\begin{tabular}{|c|c|c|c|c|c|}
\hline \multirow{3}{*}{ Değişkenler } & \multirow[b]{3}{*}{ n (\%) } & \multicolumn{4}{|c|}{ ABE } \\
\hline & & \multicolumn{2}{|c|}{ Aktif baş etme } & \multicolumn{2}{|c|}{ Pasif baş etme } \\
\hline & & Ort \pm SS & Test değeri & Ort \pm SS & Test değeri \\
\hline \multicolumn{6}{|l|}{ Yaş } \\
\hline $65-74$ & $63(64,9)$ & $1,89 \pm 0,45$ & $\chi^{2}=2,993^{* *}$ & $2,53 \pm 0,62$ & $\chi^{2}=0,544^{* *}$ \\
\hline $75-84$ & $24(24,7)$ & $2,08 \pm 0,29$ & $p=0,224$ & $2,61 \pm 0,50$ & $p=0,762$ \\
\hline 85 ve üstü & $10(10,3)$ & $1,76 \pm 0,29$ & & $2,58 \pm 0,84$ & \\
\hline \multicolumn{6}{|l|}{ Cinsiyet } \\
\hline Kadın & $55(56,7)$ & $1,95 \pm 0,49$ & $z=-0,091^{*}$ & $2,67 \pm 0,59$ & $z=-2,147^{*}$ \\
\hline Erkek & $42(43,3)$ & $1,89 \pm 0,42$ & $p=0,927$ & $2,41 \pm 0,61$ & $p=0,032$ \\
\hline \multicolumn{6}{|l|}{ Medeni Durumu } \\
\hline Evli & $85(87,6)$ & $1,91 \pm 0,41$ & $z=-0,127^{\star}$ & $2,64 \pm 0,59$ & $z=-3,594^{*}$ \\
\hline Bekar & $12(12,4)$ & $2,04 \pm 0,71$ & $p=0,899$ & $1,96 \pm 0,44$ & $p=0,000$ \\
\hline \multicolumn{6}{|l|}{ Eğitim Durumu } \\
\hline Okur-yazar değil & $15(15,5)$ & $2,18 \pm 0,54$ & $\chi^{2}=7,438^{* *}$ & $2,67 \pm 0,40$ & $\chi^{2}=0,984^{* *}$ \\
\hline İlkokul & $51(52,6)$ & $1,91 \pm 0,40$ & $p=0,059$ & $2,55 \pm 0,63$ & $\mathrm{p}=0,805$ \\
\hline Lise & $19(19,6)$ & $1,92 \pm 0,46$ & & $2,58 \pm 0,53$ & \\
\hline Üniversite & $12(12,4)$ & $1,67 \pm 0,37$ & & $2,41 \pm 0,85$ & \\
\hline \multicolumn{6}{|l|}{ Çalışma Durumu } \\
\hline Çalışıyor & $11(11,3)$ & $2,01 \pm 0,54$ & $z=-0,692^{*}$ & $2,17 \pm 0,47$ & $z=-2,142^{*}$ \\
\hline Çalışmıyor & $86(88,7)$ & $1,91 \pm 0,45$ & $p=0,489$ & $2,61 \pm 0,61$ & $p=0,032$ \\
\hline \multicolumn{6}{|l|}{ Gelir Düzeyi } \\
\hline Gelir giderden az & $13(13,4)$ & $2,05 \pm 0,53$ & $\chi^{2}=0,952^{* *}$ & $2,70 \pm 0,55$ & $\chi^{2}=7,260^{* *}$ \\
\hline Gelir gidere denk & $57(58,8)$ & $1,92 \pm 0,47$ & $p=0,621$ & $2,42 \pm 0,60$ & $p=0,027$ \\
\hline Gelir giderden fazla & $27(27,8)$ & $1,87 \pm 0,41$ & & $2,78 \pm 0,60$ & \\
\hline \multicolumn{6}{|c|}{ Birlikte Yaşadığı Kişi } \\
\hline Eş ve çocukları & $11(11,3)$ & $1,77 \pm 0,31$ & $\chi^{2}=1,001^{\star \star}$ & $2,57 \pm 0,63$ & $\chi^{2}=1,043^{* *}$ \\
\hline Yalnız & $26(26,8)$ & $2,03 \pm 0,58$ & $p=0,606$ & $2,48 \pm 0,61$ & $\mathrm{p}=0,594$ \\
\hline Eş ile & $60(61,9)$ & $1,91 \pm 0,42$ & & $2,59 \pm 0,62$ & \\
\hline
\end{tabular}

*Mann Whitney-U testi z değeri, **Kruskal Wallis testi Ki-kare değeri.

Yaşlı bireylerin deneyimledikleri ağrı ve ilaç kullanımıyla ilişkin bilgileri Tablo-2'de sunulmuştur. Yaşlı bireylerin yaklaşık yarısının $(\% 46,4)$ diz/bacak ağrısı yaşarken, bunu \%32,9 ile sırt/bel ağrısı izlemektedir. Katılımcıların $\% 27,8$ 'inin ağrıya yönelik NSAid grubunu kullandığını, \%78,4'ü de bu ağrı kesicilerden yarar gördüğü bildirmiştir. Bununla birlikte, yaşlı bireyler ağrısını en çok arttıran durumların ayakta kalmak $(\% 32)$, yürümek $(\% 27,8)$ ve yoğun iş yapmak $(\% 13,4)$ olduğunu; en çok ağrısını azaltan aktivitelerin de dinlenme $(\% 48,5)$, ağrı kesici krem uygulama $(\% 13,4)$ ve uyuma $(\% 8,2)$ olduğunu ifade etmiştir (Tablo-2).

Yaşlı bireylerin Aktif Başa Çıkma strateji toplam puanı ile herhangi bir sosyo-demografik ve ağrıyla ilgili değişkenler açısından anlamlı fark bulunmamaktadır $(p>0,05)$. Yaşlı bireylerin Pasif Başa Çıkma strateji toplam puanı ile yaş, eğitim durumu, ağrı bölgesi, kullandığı ilaç grubu, ağrıyı arttıran ve ağrıyı azaltan durumlar açısından anlamlı fark bulunmazken ( $p>0,05)$; cinsiyet, medeni durum, çalışma durumu, gelir düzeyi, ağrıya yönelik ilaç kullanımı ve genel sağlık durumu arasında istatistiksel olarak anlamlı fark bulunmuştur $(p<0,05)$ (Tablo-1 ve Tablo-2).

Yaşı bireylerin ABE genel puan ortalamaları Tablo-3'de yer almaktadır. Çalışmaya katılan yaşlı bireylerin $\mathrm{ABE}$ "Aktif Başa Çıkma" alt boyut puan ortalaması 1,92 $\pm 0,46$; "Pasif Başa Çıkma" alt boyut puan ortalaması 2,56 $\pm 0,61$ 'dir (Tablo-3). 
Tablo-2. Ağrıyla baş etme envanteri (ABE) aktif ve pasif ağrıyla başa çıkma boyutlarının bazı özelliklere göre karşılaştırılması $(n=97)$.

\begin{tabular}{|c|c|c|c|c|c|}
\hline \multirow{3}{*}{ Değişkenler } & \multirow[b]{3}{*}{ n (\%) } & \multicolumn{4}{|c|}{ ABE } \\
\hline & & \multicolumn{2}{|c|}{ Aktif baş etme } & \multicolumn{2}{|c|}{ Pasif baş etme } \\
\hline & & Ort \pm SS & Test değeri & Ort $\pm S S$ & Test değeri \\
\hline \multicolumn{6}{|c|}{ Ağrıya yönelik ilaç kullanımı } \\
\hline Var & $75(77,3)$ & $1,90 \pm 0,40$ & $z=-0,624^{*}$ & $2,68 \pm 0,51$ & $z=-3,145^{\star}$ \\
\hline Yok & $22(22,7)$ & $2,02 \pm 0,63$ & $p=0,533$ & $2,12 \pm 0,73$ & $p=0,002$ \\
\hline \multicolumn{6}{|c|}{ Kullandığı ilaç grubu } \\
\hline NSAID & $27(27,8)$ & $1,86 \pm 0,44$ & & $2,65 \pm 0,56$ & \\
\hline Zayıff opioid & $15(15,5)$ & $1,80 \pm 0,38$ & $\chi^{2}=1,896^{\star *}$ & $2,62 \pm 0,78$ & $\chi^{2}=4,029^{* *}$ \\
\hline Kuvvetli opioid & $2(2,1)$ & $1,62 \pm 0,00$ & $\mathrm{p}=0,755$ & $3,17 \pm 0,05$ & $\mathrm{p}=0,402$ \\
\hline Antidepresan & $2(2,1)$ & $2,06 \pm 0,44$ & & $2,21 \pm 0,00$ & \\
\hline Kas gevşetici & $19(19,6)$ & $1,94 \pm 0,52$ & & $2,74 \pm 0,54$ & \\
\hline Analjezik pomat & $20(20,6)$ & $2,01 \pm 0,36$ & & $2,53 \pm 0,44$ & \\
\hline \multicolumn{6}{|c|}{$\begin{array}{l}\text { Kullanılan analjezik ilaçtan } \\
\text { yarar görme }\end{array}$} \\
\hline Evet & $76(78,4)$ & $1,90 \pm 0,42$ & $z=-0,379^{\star}$ & $2,52 \pm 0,57$ & $z=-1,404^{*}$ \\
\hline Hayır & $21(21,6)$ & $2,01 \pm 0,59$ & $p=0,705$ & $2,67 \pm 0,74$ & $p=0,160$ \\
\hline \multicolumn{6}{|l|}{ Ağrı bölgesi } \\
\hline Sirt/Bel & $32(32,9)$ & $2,14 \pm 0,35$ & & $2,69 \pm 0,24$ & \\
\hline Diz/bacaklar & $45(46,4)$ & $1,92 \pm 0,28$ & $\chi^{2}=10,302^{\star *}$ & $2,65 \pm 0,47$ & $\chi^{2}=4,039^{* *}$ \\
\hline Baş/boyun & $10(10,3)$ & $2,06 \pm 0,50$ & $\mathrm{p}=0,067$ & $2,71 \pm 0,67$ & $\mathrm{p}=0,544$ \\
\hline Tüm vücut & $10(10,3)$ & $1,72 \pm 0,51$ & & $2,38 \pm 0,70$ & \\
\hline \multicolumn{6}{|c|}{$\begin{array}{l}\text { Ağrıyı arttıran durumlar } \\
\left(\mathrm{n}=81^{\mathrm{a}}\right)\end{array}$} \\
\hline Ayakta kalmak & $31(32,0)$ & $1,89 \pm 0,45$ & & $2,63 \pm 0,47$ & \\
\hline Yürümek & $27(27,8)$ & $1,89 \pm 0,31$ & $\chi^{2}=4,758^{\star *}$ & $2,59 \pm 0,61$ & $\chi^{2}=2,046^{\star *}$ \\
\hline Yoğun iş yapmak & $13(13,4)$ & $2,08 \pm 0,66$ & $\mathrm{p}=0,313$ & $2,35 \pm 0,76$ & $\mathrm{p}=0,727$ \\
\hline Stres & $5(5,2)$ & $1,60 \pm 0,28$ & & $2,81 \pm 0,84$ & \\
\hline Nem/yağmur & $5(5,2)$ & $1,65 \pm 0,40$ & & $2,15 \pm 1,06$ & \\
\hline \multicolumn{6}{|c|}{$\begin{array}{l}\text { Ağrıyı azaltan durumlar ( } n=77 \\
\text { a) }\end{array}$} \\
\hline Dinlenmek & $47(48,5)$ & $1,96 \pm 0,48$ & & $2,51 \pm 0,64$ & \\
\hline Uyumak & $8(8,2)$ & $1,60 \pm 0,16$ & $\chi^{2}=8,214^{\star \star}$ & $2,95 \pm 0,73$ & $\chi^{2}=4,299^{* *}$ \\
\hline Sicak & $6(6,2)$ & $1,64 \pm 0,32$ & $p=0,084$ & $2,16 \pm 0,94$ & $\mathrm{p}=0,367$ \\
\hline Analjezik krem & $13(13,4)$ & $1,73 \pm 0,35$ & & $2,53 \pm 0,54$ & \\
\hline Hareket/yürüyüş & $3(3,1)$ & $1,95 \pm 0,72$ & & $2,71 \pm 0,00$ & \\
\hline \multicolumn{6}{|c|}{ Genel sağlık durumu } \\
\hline İyi & $20(20,6)$ & $2,03 \pm 0,61$ & $\chi^{2}=0,522^{\star \star}$ & $2,34 \pm 0,80$ & $\chi^{2}=8,533^{\star *}$ \\
\hline Orta & $58(59,8)$ & $1,89 \pm 0,42$ & $p=0,770$ & $2,52 \pm 0,49$ & $p=0,014$ \\
\hline Kötü & $19(19,6)$ & $1,90 \pm 0,39$ & & $2,89 \pm 0,62$ & \\
\hline
\end{tabular}

*Mann Whitney-U testi z değeri, **Kruskal Wallis testi Ki-kare değeri

${ }^{a}$ Sadece yanıt verenler alınmıştır. 
Tablo-3. Yaşlıların aktif ve pasif ağrıyla başa çıkma boyutlarının genel puanları ve sonuç parametreleri.

\begin{tabular}{llc}
\hline ABE alt boyutları & OrțSS & Min.-Maks. \\
\hline Aktif baş etme stratejileri & $\mathbf{1 , 9 2 \pm 0 , 4 6}$ & $\mathbf{1 - 3 , 2 5}$ \\
1. Uzaklaşma & $2,03 \pm 0,61$ & $1-3,33$ \\
2. Ağrıyı dönüştürme & $1,60 \pm 0,76$ & $1-3,50$ \\
3. Rahatlatıcı düşünme & $2,03 \pm 0,57$ & $1-3,67$ \\
Pasif baş etme stratejileri & $\mathbf{2 , 5 6 \pm 0 , 6 1}$ & $\mathbf{1 - 3 , 7 1}$ \\
4. Endişe & $2,34 \pm 0,66$ & $1-4$ \\
5. Dinlenme & $2,78 \pm 0,77$ & $1-4$ \\
6. Geri çekilme & $2,44 \pm 0,61$ & $1-3,75$ \\
\hline
\end{tabular}

\section{TARTIŞMA}

$\mathrm{Bu}$ çalışma, yaşlı bireylerin kronik ağrıyla baş etme durumları ve etkileyen faktörlerin incelenmesi amacıyla yapılmıştır. Devam eden ya da yeterli baş edilemeyen ağrı bireyin yaşamını her yönüyle olumsuz etkileyebilmektedir (20). Ağrı, özellikle yaşlı bireylerde sık rastlanmakta ve yaşam kalitesini olumsuz etkilemektedir (21). Yapılan bu çalışmada yaşlı bireylerin ağrı puan ortalamalarının 10 puan üzerinden $6,34 \pm 2,03$ olduğu görülmekte ve yaşılıarın sıklıkla $(\% 46,4)$ diz/bacak bölgelerinde ağrı yaşadıkları, bunu $\% 32,9$ ile sırt/bel bölgesinin takip ettiği görülmektedir. Yapılan diğer çalışmalarda da çalışmamıza benzer olarak, yaşlıların ağrı puanın orta düzeyde ve en sık ağrı yaşadıkları bölgelerin diz/bacak (alt ekstremiteler) ve bel bölgesi olduğu belirlenmiştir (22-24). Bu durum, yaşlanmaya bağlı iskelet ve kas gücündeki azalmadan kaynaklanan ve özellikle vücudun tüm yükünü üzerine alan bölgelerde daha sık görüldüğünü göstermektedir.

Birçok kronik hastalıkta olduğu gibi, hastalar ağrının yoğunluğuna uyum sağlamak için çeşitli başa çıkma stratejileri kullanmaktadır (19). Bu çalışmada yaşlı bireylerin Aktif Başa Çıkma puan ortalaması 1,92 $\pm 0,46$; Pasif Başa Çıkma alt boyut puan ortalaması 2,56 $\pm 0,61$ olarak bulunmuştur. Bulgularımızda pasif baş etme puan ortalamasının daha yüksek olduğu, dolayısıyla yaşlı bireylerin ağrıyla baş etmede pasif baş etme stratejilerini daha fazla kullandığı, özellikle de dinlenme $(2,78 \pm 0,77)$ alt boyut puan ortalamasının daha fazla olduğu görülmektedir. Bununla birlikte literatürde aktif bir başa çıkma stiline sahip olmanın, hastaların sağlık hizmeti kullanımında artış sağladığı ve sağıı durumunu iyileştirdiği belirtilmektedir (25). Burada incelenen yaşlı bireyler daha düşük aktif ağrıyla başa çıkma stratejileri ve çok daha yüksek pasif ağrı ile başa çıkma puanları göstermektedir. Katılımcılarda, pasif ağrıyla başa çıkma stratejisi (özellikle dinlenme ve geri çekilme) daha önemli bulunmuştur. Bu durumun, yapılan bu çalışmada yaşlı bireyler ağrılarını arttıran durumların başında ayakta kalma (\%32) ve yürümenin $(\% 27,8)$; azaltan durumların ise; $\% 48,5$ ile dinlenme ve \%13,4 ile analjezik krem uygulama olarak ifade etmesiyle de yakından ilişkili olduğu düşünülmektedir. Çalışmamızda yaşılıarın çoğunlukla alt ekstremitelerde ağrı yaşadıklarını belirtmesi, bununla ilişkili olarak ayakta kalma ve yürümenin arttıran faktörler olmasına neden olmaktadır. Çalışmamızla benzer olarak, Saka ve Gözüm tarafından yapılan bir çalışmada da yaşılıarın en sık kullandıkları ilaç dışı öz yönetim uygulamasının dinlenme-aktivite kısıtlaması olduğu saptanmıştır (22). Bu bulgu, yaşlanmayla birlikle, dejeneratif eklem hastalıkların artmasıyla birlikte yaşlı bireylerin daha pasif ağrı ile başa çıkma stratejilerini kullanmasına yol açtığını göstermektedir. Bu muhtemelen yaşla birlikte aktivitelerde azalmayla ve bulgularımızda ayakta kalmak (\%32) ve yürümenin $(\% 27,8)$ ağrıyı arttıran faktörler arasında olmasından da kaynaklandığı düşünülmektedir.

Bu çalışmada, yaşlı bireylerden Bireylerin Aktif Başa Çıkma strateji toplam puanı ile herhangi bir sosyo-demografik ve ağrıyla ilgili değişkenler açısından anlamlı fark bulunmazken; kadın, evli, herhangi bir işte çalışmayan, geliri giderden fazla olan, ağrıya yönelik ilaç kullanan ve genel sağlık durumunu kötü olarak değerlendiren katılımcıların Pasif Başa Çıkma toplam puanının istatiksel olarak anlamlı şekilde daha yüksek 
olduğu saptanmıştır. Perrot ve arkadaşları tarafından kalça ve diz osteoartriti (OA) olan hastalarda ağrıyla başa çıkma stratejilerinin incelendiği bir çalışmada; katılımcılarının pasif ağrı ile başa çıkma stratejilerinin kullanımının OA süresi ile arttığını ve daha yaşlı ve fazla kilolu hastalarda, fiziksel aktivitesi olmayan veya majör bozukluğu olmayan hastalarda, emekli olan ve çalışmayan hastalarda, evli olmayan ve ağrı yoğunluğu daha yüksek olan hastalarda daha fazla olduğu belirtilmektedir (26). Yaşlı yetişkinlerin kronik ağrıyla baş etmesine yönelik kavram analizini oluşturma amacıyla yapılan bir çalışmada ise; ağrı yönetim stratejilerinin kadınlar arasında erkeklerden daha fazla kullanıldığı belirtilmektedir. Aynı çalışmada, kadınların bilişsel başa çıkma yöntemlerini benimseme, dini faaliyetlere katılma, psikolojik yaklaşımlar kullanma, oyalanma ve egzersiz yapma olasılıklarının daha yüksek olduğu da ifade edilmektedir (27). Bu konuda, kadınların kaynaklara daha az erişebildikleri ve bu nedenle kronik ağrıyla başa çıkmak için erişilebilir stratejilerden yararlanma olasılıklarının daha yüksek olduğu ile de açıklanmaktadır (28).

Çalışmada ağrı deneyimleyen yaşlı bireylerin, ağrı ile baş etmede sıklıkla analjezik kullanımına $(\% 77,3)$ başvurduklarını ve \%78,4'ü kullandıkları analjezik ilaçtan yarar gördüklerini belirtmektedir. Tanrıverdi ve arkadaşları tarafından yapılan bir çalışmada ise yaşılıarın ağrı ile baş etmede sıklıkla ilk tercihi evde ağrı kesici kullanmak $(\% 35,9)$ olduğu, bunu bir sağlık kuruluşuna başvurma $(\% 26,9)$, ağrının kendiliğinden geçmesini bekleme (\%20) ve 17,2'sinin de farklı yöntemler deneme gibi baş etme yöntemlerini takip ettiği belirtilmiştir. Özel ve arkadaşları tarafından yapılan bir çalışmada yaşılıarın $\% 96,3$ 'ünün ağrı kesici ve bu yaşlı bireylerin de \%58'nin non-opioid analjezik kullandıkları görülmüştür (29). Bıyık ve arkadaşları yaşılırın analjezik ilaç kullanma oranını \%42,9 olarak bulmuştur (30). Yapılan başka bir çalışmada ise yaşlıların analjezik kullanım oranları daha yüksek $(\% 90,6)$ saptamıştır (31). Yapılan bu çalışmanın sonuçlarında ağrı ile baş etmede ilk sırada analjezik kullanımına yönelik elde edilen sonuçlar diğer çalışma sonuçları ile tutarıdır.

Kronik ağrı ile başa çıkmada sosyal, fiziksel, psikolojik ve demografik özellikler, bireyin yaşam koşulları, baş etmeye yönelik deneyimleri ve bilgisi gibi çeşitli faktörler etkili olabilmektedir. Yaşı bireyin tercih ettiği başa çıkma stratejileri ile süreci olumlu ya da olumsuz etkileyebilmektedir. Yapılan bu çalışmada yaşlı bireylerin pasif baş etme stratejilerini, aktif baş etme stratejilerine göre daha fazla kullandığı görülmektedir.

\section{SONUÇ}

Yaşılıarın çoğu, günlük aktivitelerini önemli ölçüde değiştiren ve sağlık hizmetleri üzerinde muazzam bir yük oluşturan kronik ağrıdan muzdariptir. Bununla birlikte, bu çalışmanın sonucu yaşlı bireylerin pasif baş etme stratejilerini, aktif baş etme stratejilerine göre daha fazla kullandığını göstermektedir. Sağlık profesyonellerinin, özellikle yaşlılık döneminde sağlık problemlerinin artması ve aktivite düzeyinin azalması ile birlikte sık karşılaşılan bir problem olan ağrının değerlendirmesi ve baş etme uygulamalarını bilmesi önemlidir. Özellikle, kronik ağrısı olan yaşlı bireylerde uzaklaşma, ağrıyı dönüştürme ve rahatlatıcı düşünme gibi aktif başa çıkma stratejilerinin daha fazla kullanımına yönelik terapötik ve bilişseldavranışçı yaklaşımların kullanımının gerekli olacağını düşündürmektedir. Bu konuda mevcut durumu ortaya koyan bu çalışmanın, farkındalık oluşturmaya ve yaşlı bireylerin yaşam kalitesini artırmaya yönelik stratejilerin geliştirilmesine katkı sağlayacağı düşünülmektedir.

\section{ARAŞTIRMANIN SINIRLILIKLARI}

Tüm bu bulgularla birlikte, çalışmanın doğru değerlendirilebilmesi için bazı sınırlılıklarının göz önünde bulundurulması gerekmektedir. İlk olarak, katılımcıların ağrı düzeyi VAS ile belirlenmeye çalışılsa da, ABE'nin hem öz bildirim yöntemine dayanması hem de baş etme yöntemlerini geriye dönük değerlendirmesi bir kısıtılıktır. İkincisi çalışmanın başlangıcında daha fazla yaşlı bireye ulaşılmak amaçlansa da, çalışmanın yapıldığı dönemin sonuna doğru tüm dünyada ve ülkemizde pandemi sürecinin başlaması ve ardından gelen kısıtlamalarla yüz yüze veri toplanması kesintiye uğramıştır. Ayrıca, çalışmaya alınma kriterleri arasında en az 3 aydır ağrı şikâyeti olan bireylerin alınması (ağrı bildirmeyen ya da 3 aydan daha az süreden ağrısı olanların dışlanması) nedeniyle daha az yaşlı bireye ulaşılmıştır. Bu alanda daha geniş popülasyon ve farklı kliniklerde yatan yaşlı bireylerle yeni çalışmaların yapılması önerilmektedir.

Çıkar çatışması: Bu yayına ilişkin yazarların her hangi bir çıkar çatışması yoktur. 


\section{Kaynaklar}

1. WHO. Ageing and health. Key facts. 5 February 2018 Erişim adresi: https://www.who.int/news-room/factsheets/detail/ageing-and-health Erişim tarihi: 16.02.2021.

2. Çilingir D, Bulut E. Yaşı bireylerde ağrıya yaklaşım. Anadolu Hemşirelik ve Sağlık Bilimleri Dergisi, 2017; 20: 2: 143-53.

3. Hocaoğlu A, Berk HÖS, Ketenci A. Ağrıyla baş etme envanteri'nin geçerlik ve güvenirlik çalışması. Agri 2019; 31 (1): 32-41.

4. Dahlhamer J, Lucas J, Zelaya, C, et al. Prevalence of chronic pain and high-impact chronic pain among adults - United States, 2016. MMWR Morb Mortal Wkly Rep 2018; 67: 1001-6.

5. Patel KV, Guralnik JM, Dansie EJ, Turk DC. Prevalence and impact of pain among older adults in the United States: findings from the 2011 National Health and Aging Trends Study. Pain 2013; 154: 2649-57.

6. Jackson T, Chen H, lezzi T, Yee M, Chen F. Prevalence and correlates of chronic pain in a random population study of adults in Chongqing, China. Clin J Pain 2014; 3: 346-52.

7. Reid MC, Eccleston C, Pillemer K. Management of chronic pain in older adults. BMJ Clinical Research 2015; 350: 27-30.

8. Abdulla A, Adams N, Bone M, et al. Guidance on the management of pain in older people. Age Ageing 2013; 42 (Suppl 1): 1-57.

9. American Geriatrics Society Panel on Persistent Pain in Older Persons. Pharmacological management of persistent pain in older persons. J Am Geriatr Soc 2009; 57: 1331-46.

10. Institute of Medicine (US) Committee on Advancing Pain Research, Care, and Education. Relieving pain in America: a blueprint for transforming prevention, care, education, and research. Washington (DC): National Academies Press (US); 2011.

11. Babadağ B, Balcı Alparslan G. Yaşlandım, ağrım var!, Hemşirelikte Eğitim ve Araştırma Dergisi 2016; 13 (2): 67-71.

12. Tennen H, Affleck G, Zautra A. Depression history and coping with chronic pain: A daily process analysis. Health Psychology 2006; 25 (3), 370-9.

13. Wollaars MM, Post MW, van Asbeck FW, Brand N. Spinal cord injury pain: the influence of psychologic factors and impact on quality of life. Clin J Pain 2007 Jun; 23 (5): 383-91.

14. Molton IR, Stoelb BL, Jensen MP, Ehde DM, Raichle KA, Cardenas DD. Psychosocial factors and adjustment to chronic pain in spinal cord injury: replication and cross-validation. J Rehabil Res Dev. 2009; 46 (1): 31-42.

15. Kantek F, Kabukcuoğlu K. Burnout in nurses: A meta analysis of related factors\&lt;p\&gt; Hemşirelerde tükenmişlik: İlgili faktörlerin meta analizi. Journal of Human Sciences 2017; 14 (2): 1242- 54.

16. Vargas-Schaffer G, Cogan J. Patient therapeutic education: placing the patient at the centre of the WHO analgesic ladder. Can Fam Physician. 2014 Mar; 60 (3): 235-41.

17. Hawker GA, Mian S, Kendzerska T, French M. Measures of adult pain. Arthritis Care Res 2011; 63 (S11): $240-52$.

18. Uzunoğlu S, Çiçin İ. Kanser hastalarında ağırıa yaklaşım. Klinik Gelişim Dergisi 2011; 24 (3): 14-20.

19. Kraaimaat FW, Evers AW. Pain-coping strategies in chronic pain patients: psychometric characteristics of the Pain-Coping Inventory (PCI). Int J Behav Med 2003; 10: 343-63.

20. Allard P, Maunsell E, Labbé J, Dorval M. Educational interventions to improve cancer pain control: a systematic review. J Palliat Med 2001; 4 (2): 191-203.

21. Lemos BDO, Cunha AMRD, Cesarino CB, Martins MRI. The impact of chronic pain on functionality and quality of life of the elderly. BrJP 2019; 2 (3): 237-41.

22. Saka SD, Gözüm S. Toplumda yaşayan yaşılıarda ağrı prevalansı ve ağrı öz yönetim uygulamaları, Cukurova Med J 2020; 45 (2): 595-603.

23. Çetin Y, Yağcı N, Yürekdeler Şahin N. Kronik kas-iskelet ağrısı olan yaşıılarda kognitif düzeyin ağrı algısına etkisi, Mersin Univ Saglık Bilim Derg 2015; (8) 3: 71-8.

24. Şimşek TT, Yumin ET, Öztürk A, Sertel M, Yumin M. Ev ortamında yaşayan yaşlı bireylerde ağrı ile sağlık durumu, mobilite ve günlük yaşam aktivite düzeyi arasındaki ilişki. Türk Fiz Tıp Rehab Derg 2011; 57: 216-20.

25.van Scherpenseel MC. Pain coping style and health care use in patients with early knee and/or hip osteoarthritis: 10-year CHECK cohort study (Master's thesis) 2019. 
26. Perrot S, Poiraudeau S, Kabir M, et al. Active or passive pain coping strategies in hip and knee osteoarthritis? Results of a national survey of 4,719 patients in a primary care setting. Arthritis Rheum 2008 Nov 15; 59 (11): 1555-62.

27. Ho LY. A concept analysis of coping with chronic pain in older adults. Pain Management Nursing $2019 ; 20$ (6): 563-71.

28.Dunn KS, Horgas AL. Religious and nonreligious coping in older adults experiencing chronic pain. Pain Management Nursing 2004; 5 (1): 19-28.

29. Özel F, Yıldırım Y, Fadıloğlu Ç. Huzurevinde yaşayan yaşılıarda ağrı yönetimi, Ağrı 2014; 26 (2): 57-64.

30. Bıyık A, Özgür G, Özsoy SA, Erefe İ. Huzurevinde yaşayan yaşlıların fiziksel sağlık sorunları ve hastalıklarına yönelik ilaç kullanma davranışları. Geriatri 2002; 5 (2): 68-74.

31. Güler G, Güler N, Kocataş S, Akgül N. Yaşlıların sağlık bakım gereksinimleri. Cumhuriyet Tıp Derg 2009; 31 (4): 367-73. 